\title{
IMPORTANCE OF COLOUR MARKETING IN THE EVOLUTIVE MARKETING CONCEPT
}

\author{
Noémi Hajdú \\ associate professor, University of Miskolc, Marketing and Tourism Institute \\ 3515 Miskolc, Miskolc-Egyetemváros, e-mail: hajdu.noemi@uni-miskolc.hu
}

\begin{abstract}
Colours play an important role in marketing, especially in competitive branding in the market when it comes to reaching the target audience and meeting the expectations and demand of the consumers. Human senses are of great importance in achieving a unique and distinctive position for different product categories. The marketers should use the harmony of colours to gain a successful foothold in the various markets. The aim of this study is to describe the different meanings of colours in different cultures.
\end{abstract}

Keywords: marketing evolution, colour psychology, colour marketing

\section{Introduction}

There is a lot of competition in the market to meet consumer expectations and demand. Producers, retailers, and service providers are trying to differentiate themselves. The immense importance of brands is to achieve a unique and prominent position in the minds of the target customers. Human senses (sight, hearing, taste, touch, and smell) are crucial to perceive the world around us. Indeed, the sense of sight helps us identify different companies and brands and influences brand awareness. The question is how marketing methods have adapted to the emerging environmental changes.

\subsection{Evolutive marketing concept}

The new paradigm shift in marketing is referred to by Kotler et al. (2010, 2016, 2021) as Marketing 1.0 to Marketing 5.0. This evolutionary marketing concept is explained in more detail below.

In the period of Marketing 1.0 (Kotler et al., 2010), the product-centric approach was characteristic. The best example is Henry Ford's Model T, which was a basic product at an affordable price. His famous saying was 'any customer can have a car in any colour as long as it is black'. The marketer's job is to meet the needs and expectations of the consumer, be the best in the industry competition and make higher profits.

The next concept, Marketing 2.0 (Kotler et al., 2010), means a consumer-centric aspect where consumers are well informed thanks to smart information technology. As a result, the different offers can be compared quickly and easily. Marketing research can be used to evaluate and monitor changes in consumer preferences and behaviour. Companies adapt their product and service offerings to the needs of individual target group segments. The importance of loyalty programmes and cards has increased during this period. The goal of marketers is to identify the different needs of different segments, provide optimal product value to each segment, and make smart sales. 
The marketing 3.0 perspective (Kotler et al., 2010) is a human-centred stage where well-informed consumers make conscious choices (in the social, environmental, and societal sense) when selecting products. It is also a holistic, value-based concept that involves solving a social problem. The role of product and service selling is to create a social impact that captures consumer attention.

In terms of Marketing 4.0 (Kotler et al., 2016, p.46), "online and offline interactions between companies and customers are combined". Effective marketing requires a simultaneous offline and online presence. In the digital economy, customers contribute to content, become co-creators, and personalise the company's products and services according to market demand. Communication is more lively, interactive and two-way, and customers can respond to companies' marketing messages through social media. The goal of marketers is to attract and engage consumers.

The theory of Marketing 5.0 (Kotler et al., 2021, p. 6) 'is the application of technology that mimics humans to create, communicate, deliver, and enhance value for customers'. The term interprets the changes in consumer behaviour due to digitalization and includes devices such as artificial intelligence (AI), sensors, robotics, augmented and virtual reality (AR and VR), the Internet of Things (IoT), and blockchain. With the digital footprint, consumer habits are more familiar than ever before, which can improve the customer experience. The effort for marketers is to anticipate this and offer customers something they are not even aware of. Colours and symbols play a critical role in the rise of multisensory.

\section{Colour marketing}

Colours and colour choices influence our perception, which is important in packaging and branding. 'The importance of the environment and its visual components on customers' perception of spaces has been researched in various environments such as shops, malls, restaurants, offices and hospitals' (Siamionava et al., 2018, p.85.).

The psychological effect of colours on behaviour is biologically and culturally learned and depends on the hue, brightness and chroma of the colour (Elliot and Maier, 2007). Colours influence customers' emotions (Donovan and Rossiter, 1982) and the time they spend in a shop (Bellizzi and Hite, 1992).

The aim of the current study is to describe the different meanings of colours.

\subsection{Features of colour marketing}

'Colour is a crucial component of the visual dimension of a spatial environment' (Kotler, 1973), which can be grouped according to its effect on mood, distinguishing between cold, warm, and neutral colours. Cold colours are blues, greens and their tones, warm colours are reds and yellows and their mixtures (such as orange and brown), and neutral colours are mostly different shades of grey, white and black (Khattak et al., 2018; Kocsis, 2019).

According to Hauff (2018), primary colours are blue, yellow, and red; secondary colours can be mixed from these three hues, which is also known as colour mixing, such as orange (an alloy of red and yellow) or green, which can be obtained from a mixture of yellow and blue, but also contains violet.

Pure colours are primary or secondary colours to which no black, white, or other hue has been added. They are distinctively intense and bright colours. They are usually used for children's toys and summer clothing. A pastel colour can be any colour to which a shade of white has been added, that is, a lighter, weaker shade of itself.

It is also important to note that analogous colours are, among other things, the shades that are adjacent to each other on the colour wheel. Moreover, the meaning of monochromatic colours obscures the fact 
that a colour palette consists only of different shades of a selected colour, ranging from light to dark (Hauff, 2018). Cugelman (2020, p. 12) refers to saturation as the phenomenon of a light colour constantly fading into grey across an entire palette.

\subsection{Meaning of the different colours in Europe}

The human eye can distinguish up to 10 million colours (Mukamal, 2017). There are almost infinite ways to select a colour or analyse its meaning. Each colour has its own meaning and conveys emotion, a psychological effect. Moreover, certain colour combinations are common, for example, in brands that belong to the same industry. I summarise the meaning of colours based on the following literature Füredi (2014), Petschner (2019), and Velarde (2019).

Red is an exciting, adventurous, dynamic colour that symbolizes love and passion. It is the most used colour to attract attention. In marketing, it has been recognized to increase the heart rate, thus providing an incentive to buy. It encourages quick action, which is why red is often used for discounts and advertising. The colour red has an appetite stimulating effect. It is no coincidence that it is used in the logos of almost all major restaurant chains. For example, a red logo is used by Coca Cola, Kellogg's, CNN, BBC, Canon, Virgin and Disney.

Orange suggests warmth, friendliness, reliability, and urges caution, which is why it is used in road repair. This colour stimulates activity, strengthens the immune system, and increases appetite. In marketing, it encourages action and purchases, which is why it is often used as a colour for sign-up buttons, as it can lead to higher sales. This colour promotes team spirit and influences optimistic feelings, which is why many sports teams use it for their logo and jerseys. The colour orange can be associated with the psychology of colours, even affordability and value for money, which is why coupon sites are preferred. Orange can be found in the logo of amazon, Fanta at Harley Davidson and Mastercard among others.

Lemon yellow represents warmth and energy, promotes communication, and stimulates creativity. Activates memory and increases concentration. Yellow stimulates the brain, which is perhaps why it is the warning colour used for warning signs such as slippery floors or warnings about car racing. Babies also respond to this colour first, which is why many baby toy manufacturers use it. However, too much yellow triggers discomfort, so you need to be careful about balance when using this colour. Yellow attracts attention because it stands out from the crowd. That's why it often appears in brand logos, such as McDonald's, Shell, DHL, Ikea, and Nikon.

Green is a symbol of nature and peace, and of a harmonious and healthy life. It is the most common colour that surrounds us in nature, which is why interior designers often use it as a background. The word green expresses environmental awareness, and it is no coincidence that it is the main colour of environmental companies. Its calming effects are well known, which is why it is used in hospitals and doctors' offices, and can not only relieve anxiety, but even depression. It is also used in many stores for its calming effect. The green logo is used by Starbucks, Animal Planet, Spotify, and Carlsberg, for example.

Blue is the colour of the ocean and the sky, and therefore ubiquitous in our lives. Like green, it radiates calm and serenity. It stimulates the production of calming chemicals in our bodies, which is why it is often used in the bedroom, while it increases work efficiency and enhances intuition. It suggests reliability, security, commitment, honesty, and intelligence, which is why it is recommended to wear blue for a job interview. Major social media platforms such as Facebook, Twitter, LinkedIn as well as banks (American Express, Visa) and IT companies (Dell, HP, Intel) use the logo of the colour blue. 
In psychology, the colour purple is the colour of wisdom, success, wealth, respect, and luxury, and is associated with creativity and intuition. It also has a calming effect on marketing, which is why it is used in anti-aging cosmetic products. Blue is a blend of the energy of safety and red, the most used colour for luxury brands. It also encourages creativity and problem solving. Milka, FedEx, Hallmark and Cadbury also use this colour.

If we mix the passion of red with the purity of white, we get the pale pink associated with romance. Nowadays it is a particularly feminine colour, which is why it catches the eye of the ladies. The phenomenon known as the pink tax means that the products offered to the target group of pink women are more expensive than those of their male counterparts. Bright pink, like red, can raise blood pressure, heart rate and pulse, which inspires action and confidence, while pale pink has a western appeal. Pink also highlights the post-sugar logos of Barbie, Taco Bell, and Victoria's Secret.

Brown is the colour of all natural and organic products that come in contact with the earth. The association with brown is primarily about stability, reliability, and care. It is considered a neutral colour and is preferred by designers as a background colour because of its calming, harmonizing effect. The colour is extremely rare, among companies it is perhaps best known for M\&M, who use it.

The colour white represents reliability, perfection, purity, innocence, and health. It symbolises purity, which is why doctors wear white coats and brides traditionally marry in white dresses. It exudes elegance and luxury, just like black, although it is also a colour of minimalist style. In interior design, it expands and enlarges space. Worldwide, most t-shirts are sold in white, and most shades available in stores are also white. It is combined with other colours in logos, such as Tesla, The North Face, Mini and Crocs.

Black is an extremely powerful colour in every respect. On the one hand, it is a contradictory colour because it shows elegance, sophistication, lightness, independence, but at the same time it represents coldness, sadness, and - in Western culture - mourning. It is a classic colour for clothing, probably because of the visually slimming and timeless fashion of black dresses and because of their identification with elegance (black is the colour of tuxedos, limousines, judges' robes, church clothes). The combination of black and white is a perennial classic and therefore always found in the repertoire of prestigious brands such as WWF, Adidas, Puma or Chanel. When the emphasis is on luxury and opulence, black and gold or black and silver is a must.

Grey is also considered a compromise colour, probably because it lies between black and white. It is a completely neutral colour that gives a sense of formality and elegance. People often associate the colour grey with silence, peace and therefore complete tranquilly. It is used by major car brands such as Toyota, Nissan, Mercedes-Benz and in other industries (Apple, Nestlé, Swarowski).

\subsection{Meaning of the different colours in the other culture}

Unlike European culture, which is primarily Christian, the meaning of colours and the resulting psychological impact may be different in the cultures of other continents and landscapes.

Perhaps one of the biggest differences between Western and Eastern cultures is the meaning of the colours white and black. In China, Japan, and India, white symbolises mourning, death, and transience.

In China, yellow is a noble, sacred colour, an idea derived from the lustre of gold, a colour of enlightened thought, making gold a symbol of glory and nobility (Kocsis, 2019). The colour red is also significant in Chinese culture because it represents longevity, and brides' dresses are not white, as is common in Christian culture, but red.

In Japan, the colour red has a double meaning. On the one hand, it can be a symbol of anger in some cases, but as in China, it also represents happiness and joy. Yellow is the colour of courage and nobility, 
and green is the colour of eternal life (Kumar, 2017, p.11). Black represents experience, the best example of this in martial arts is the black belt (Petschner, 2018).

Orange plays a prominent role, in part because of its Hindu and Buddhist significance. The meaning of the colour itself is sacred, which is why Buddhist's wear orange (Brooks, 2016).

In Armenia, Syria, Iran, and Mexico, blue is the colour of death because it is the gateway to heaven: the sky is blue (Kocsis, 2019). In Thailand, purple is the colour of mourning (Shutterstock, 2020).

\section{Summary and conclusion}

The colour of products and packaging has a major impact on consumer perception and buying behaviour. It is a powerful marketing tool, but according to Gorn et al. (1997, p. 1387), 'marketers' decisions about the use of colour are often based on intuition and anecdotal evidence rather than solid theoretical foundations'. Colour psychology and colour marketing have a broad theoretical background. It is worth looking into, as Chebat and Morrin's $(2005$, p. 194.) research shows 'that mall decoration can have a significant impact on customers' perceptions not only of their surroundings, but also of the quality of the products sold in the environment'.

Different colours have different meanings in Western and Eastern cultures; therefore colours can contribute to successful market entry in international marketing.

\section{Literature}

[1] Bellizzi, J. A., Hite, R. E. (1992). Environmental colour, consumer feelings, and purchase likelihood. Psychology \& Marketing, 9(5), 347-363. https://doi.org/10.1002/mar.4220090502

[2] Brooks, R. (2016). Colours and their meanings around the world. https://www.kinternational.com/blog/colour-meanings-around-theworld/?fbclid=IwAR0DzHCp2V8mxMCjYzkANotFNExT3R9T1I6rf0HPFMP4GbRPGnwimE jN8j0 (downloaded: 04.10.2021)

[3] Chebat, J.-C., Morrin, M. (2007). Colours and cultures: Exploring the effects of mall décor on consumer perceptions. Journal of Business Research, 6, 189-196. https://doi.org/10.1016/j.jbusres.2006.11.003

[4] Cherry, K. (2020). Colour Psychology: Does it affect how You feel? How colours impact moods, feelings, and behaviors. https://www.verywellmind.com/colour-psychology-2795824 (downloaded: 04.10.2021)

[5] Cugelman, B. (2020). Colour Psychology. https://www.alterspark.com/wpcontent/uploads/colour_psychology_book_alterspark_25_42347951.pdf_ (downloaded: 05.09.2021)

[6] Donovan, R., Rossiter, J. (1982). Store atmosphere: an environmental psychology approach. Journal of Retailing, 58, 34-57.

[7] Elliot, A., Maier, M. A. (2012). Chapter two - Colour-in-Context Theory. In Devine, P., Plant, A. (Eds.), Advances in Experimental Social Psychology (45. pp. 61-125). Academic Press. https://doi.org/10.1016/B978-0-12-394286-9.00002-0

[8] Füredi, K. (2014). Színpszichológia. https://pszichozona.hu/szinpszichologia (downloaded: $08.10 .2021)$

[9] Gorn, G. J., Chattopadhyay, A., Yi, T., Dahl, D. W. (1997). Effects of colour as an executional cue in advertising: they're in the shade. Management Science, 43(10), 1387-1400. https://doi.org/10.1287/mnsc.43.10.1387 
[10] Hauff, A. (2018). The know-it-all guide to colour psychology in marketing + the best hex chart, CoSchedule Blog, 2018.08.29. https://coschedule.com/blog/colour-psychologymarketing/\#basics (downloaded: 04.10.2021)

[11] Khattak, S. R., Ali, H., Khan, H., Shah, M. (2018). Colour Psychology in Marketing. Journal of Business and Tourism, 4(1), January-June, 2018.

[12] Kocsis, Z. (2019). Szinpszichológia a marketingben, Válts online weboldalra. https://valts.online/szinpszichologia-a-marketingben/ (downloaded: 08.08.2021)

[13] Kotler, P. (1973). Atmospherics as a marketing tool. Journal of Retailing, 49(4), 48-64.

[14] Kotler, P., Kartajaya, H., Setiawan, I. (2010). Marketing 3.0: From Products to Customers to the Human Spirit. John Wiley \& Sons. https://doi.org/10.1002/9781118257883

[15] Kotler, P., Kartajaya, H., Setiawan, I. (2016). Marketing 4.0: Moving from Traditional to Digital. Wiley.

[16] Kotler, P., Kartajaya, H., Setiawan, I. (2021). Marketing 5.0: Technology for Humanity. Wiley.

[17] Kumar, J. S. (2017). The psychology of colour influences consumers' buying behaviour - A diagnostic study. Ushus-Journal of Business Management, 16(4), 1-13. https://doi.org/10.12725/ujbm.41.1

[18] Petschner, A. (2019). Ha gyorsétterem, akkor piros - ha közösségi oldal, akkor kék: Színek a brandépitésben.

https://konzervtelefon.blog.hu/2019/01/19/ha_gyorsetterem_akkor_piros_ha_kozossegi_oldal_ akkor_kek_szinek_a_brandepitesben (downloaded: 08.10.2021)

[19] Shutterstock (2020). The meaning of colours in cultures around the world. https://www.shutterstock.com/blog/colour-symbolism-and-meanings-around-the-world (downloaded: 08.10.2021)

[20] Siamionava, K., Slevitch, L., Tomas, S. R. (2018). Effects of spatial colours on guests' perceptions of a hotel room. International Journal of Hospitality Management, 70, 85-94. https://doi.org/10.1016/j.ijhm.2017.10.025

[21] Velarde, O. (2019). Colour Psychology in Marketing: The ultimate guide. https://visme.co/blog/colour-psychology-in-marketing-the-ultimate-guide/ (downloaded: $08.10 .2021)$ 